\title{
Rapid reversal of heart failure in a patient with phaeochromocytoma and catecholamine-induced cardiomyopathy who was treated with captopril
}

\author{
Matthias Salathe, Philipp Weiss, Rudolf Ritz
}

\begin{abstract}
A patient with a phaeochromocytoma and severe left ventricular heart failure caused by a catecholamine-induced cardiomyopathy is described. The clinical signs of congestive heart failure resolved rapidly on treatment with captopril and myocardial performance became normal within two weeks of medical treatment with captopril for one week and with captopril in combination with phenoxybenzamine for another week.
\end{abstract}

(Br Heart J 1992;68:527-8)

Despite active secretion of catecholamines phaeochromocytoma is associated with normotension or even with considerable hypotension in up to $30 \%$ of cases. ${ }^{1}$ We report the case of a patient with a phaeochromocytoma and acute and severe left ventricular heart failure caused by a histologically confirmed catecholamine-induced cardiomyopathy.

\section{Case report}

A 42 year old man was admitted to a district hospital complaining of a chronic unproductive cough. Five years earlier his heart size had been normal, but two months before admission a slight cardiac enlargement had been noticed on a chest $x$ ray. During a flexible bronchoscopy (to rule out a bronchial adenoma) he became tachycardiac and hypertensive $(220 / 120 \mathrm{~mm} \mathrm{Hg}$ ). Propranolol (1 mg) was injected intravenously. Respiratory distress rapidly developed and he needed artifical ventilation. A chest $x$ ray showed pulmonary oedema and an enlarged heart, and the electrocardiogram showed sinus tachycardia and ST segment elevations in leads V1 to V6. $M$ mode and cross sectional transthoracic echocardiography showed global hypokinesia of the left ventricle. Treatment with glyceryl trinitrate, dopamine, dobutamine, and diuretics was started. The patient was transferred to the intensive care unit in our hospital.

A coronary angiogram did not show left main stem disease. Left ventriculography showed global hypokinesia despite inotropic stimulation. The left end diastolic pressure was increased to $17 \mathrm{~mm} \mathrm{Hg}$ and the ejection fraction was reduced to $46 \%$. An endomyo- cardial biopsy specimen showed focal fibre necrosis and infiltration of monocytes and lymphocytes (figure).

During the next two days the patient's blood pressure fluctuated considerably. On the third day extubation could be performed and treatment with vasopressors was stopped. The patient became again hypertensive; systolic blood pressure peaked at over $230 \mathrm{~mm} \mathrm{Hg}$. Medical treatment with diuretics and nifedipine was unsuccessful. Captopril, however, controlled blood pressure and improved the clinical signs of left ventricular failure within eight hours.

A tenfold increase in the catecholamine concentration in a 24 hour urinary sample confirmed the suspected phaeochromocytoma. A computer tomogram of the abdomen showed a mass of $5.5 \times 3.5 \mathrm{~cm}$ in diameter in the region of the left adrenal gland. This mass was the only area to show increased uptake of ${ }^{131}$ I-meta-iodobenzyl-guanidine. The appearance of the endomyocardial biopsy specimen was consistent with a catecholamine-induced cardiomyopathy. One week later treatment with captopril was started and the patient was also given increasing doses of the $\alpha$ antagonist, phenoxybenzamine (up to $60 \mathrm{mg}$ a day). A week later, a radionuclide angiocardiography showed a complete normal myocardial performance and the calculated ejection fraction was $65 \%$.

The phaeochromocytoma was removed one week later without complication. One week after operation the serum and urinary concentrations of catecholamines were within the normal ranges.

\section{Discussion}

Acute heart failure caused by a catecholamine-induced cardiomyopathy may be the only symptom of a phaeochromocytoma. ${ }^{2}$ Heart enlargement two months before admission suggested the development of cardiomyopathy in our patient. Furthermore, the endomyocardial biopsy findings were consistent with the diagnosis of a catecholamineinduced cardiomyopathy ${ }^{3}$ (figure). Treatment with a $\beta$ blocker rapidly led to pulmonary oedema in our patient, because of unopposed $\alpha$ adrenergic stimulation. ${ }^{45}$

Catecholamine-induced cardiomyopathy has been improved or reversed by surgical removal of the catecholamine-secreting tumour or by medical with $\alpha$ blockers over 


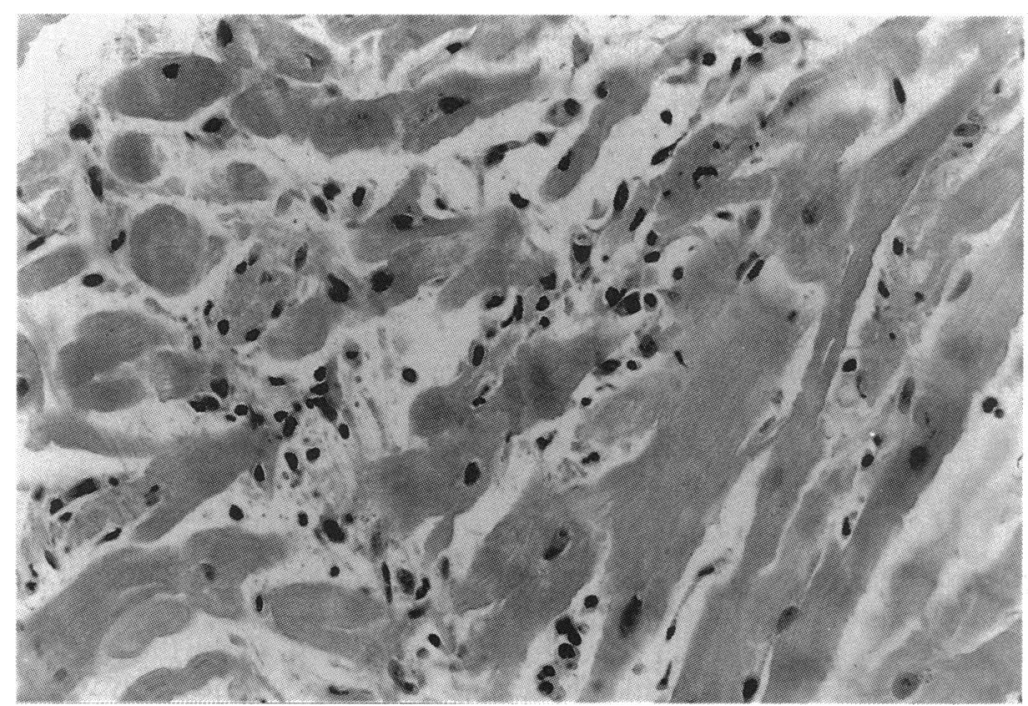

Endomyocardial biopsy specimen showing fibre necrosis surrounded by infiltrations with monocytes and lymphocytes that is typical of catecholamine-induced cardiomyopathy (haematoxylin and eosin, original magnification, $\times 350$ ).

several weeks. ${ }^{6-8}$ In our patient the clinical signs of congestive heart failure improved within eight hours of treatment with captopril. More important, the abnormally low initial ejection fraction (despite inotropic stimulation) became normal after medical treatment with captopril alone and then when captopril was given in combination with phenoxybenzamine for a total of only two weeks. This increase in the ejection fraction was considerable and overcomes the fact that the two values were measured by two different methods. $\alpha$ Blockade would not have restored cardiac performance in such a short time. We believe therefore that captopril alone or in combination with phenoxybenzamine was responsible for the rapid return to normal of our patient's cardiac performance.

The hypothesis is supported by published experimental data. Hu showed that captopril inhibited the development of the catecholamine-induced cardiomyopathy in rats with phaeochromocytomas. ${ }^{9}$ It is unlikely that this effect was the result of captopril's antihypertensive efficacy, because the non-specific vasodilator hydralazine has no effect on the development of catecholamine-induced cardiomyopathy though it normalised blood pressure in the same rats. ${ }^{10}$ The difference between captopril and hydralazine can be explained by their different influences on the local cardiac renin-angiotensin system. ${ }^{11}$ Angiotensin increases the growth and proliferation rate of myocytes in vitro. Hydralazine activates mycocytological renin activity, which in turn stimulates cardiac hypertrophy. In contrast, captopril inhibits the cardiac renin-angiotensin axis. ${ }^{11}$ This is one possible mechanism, by which captopril may counteract catecholamine-induced cardiomyopathy. Furthermore, free radicals from long chain fatty acids, which act as direct myocardial toxins, have been described in phaeochromocytoma. ${ }^{12}$ Captopril, an angotensin converting enxyme inhibitor with sulphydryl groups, may be able to scavenge these free radicals. ${ }^{13}$

We thank Dr M Mihatsch, professor of pathology, for the photograph.

1 Engelman K. Phaeochromocytoma. Clin Endocrinol Metab 1977;6:769-97.

2 Sardesai SH, Mourant AJ, Sivathandon Y, Farrow R, Gibbons DO. Phaeochromocytoma and catecholamine induced cardiomyopathy presenting as heart failure. $\mathrm{Br}$ Heart J 1990;63:234-7

3 vanVliet PD, Burchell HB, Titus JL. Focal myocarditis associated with phaeochromocytoma. N Engl J Med 1966; 274:1102-8.

4 Sloand EM, Thompson BT. Propranolol-induced pulmonary edema and shock in a patient with phaeochromocytoma. Arch Intern Med 1984;144:173-4.

5 Wark JD, Larkins RG. Pulmonary oedema after propranolol therapy in two cases of phaeochromocytoma. $\mathrm{Br}$ Med $J$ 1978;1:1395-6.

6 Stenström G, Holmberg S. Cardiomyopathy in phaeochromocytoma: report of a case with a 16-year follow up after surgery and review of the literature. Eur Heart $J$ 1985;6:539-44.

7 Wood R, Commerford PJ, Rose AG, Tooke A. Reversible catecholamine-induced cardiomyopathy. Am Heart J 1991;121:610-3.

8 Imperato-McGinley J, Gautier T, Ehlers K, Zullo MA, Goldstein DS, Vaughan ED, Jr. Reversibility of catecholamine-induced dilated cardiomyopathy in a child with a phaeochromocytoma. $N$ Engl J Med 1987;316: 793-7.

9 Hu ZW, Billingham M, Tuck M, Hoffman BB. Captopril improves hypertension and cardiomyopathy in rats with phaeochromocytoma. Hypertension 1990;15:210-5.

10 Rosenbaum JS, Ginsburg R, Billingham ME, Hoffmann BB. Effect of adrenergic receptor antagonists on cardiac morphological and functional alterations in rats harboring phaeochromocytoma. J Pharmacol Exp Ther 1987;241: 354-9.

11 Dzau VJ. Cardiac renin-angiotensin system. Molecular and functional aspects. Am J Med 1988;84(suppl 3A):22-7.

12 Singal PK, Kapur N, Dhilon KS. Role of free radicals in catecholamine induced cardiomyopathy. Can J Physiol Pharmacol 1982;60:1390-7.

13 Przyklenk K, Kloner RA. Relationship between structure and effects of ACE inhibitors: comparative effects in myocardial ischaemic/reperfusion injury. $\mathrm{Br} J \mathrm{Clin}$ Pharmacol 1989;28(suppl 2):167-75. 